
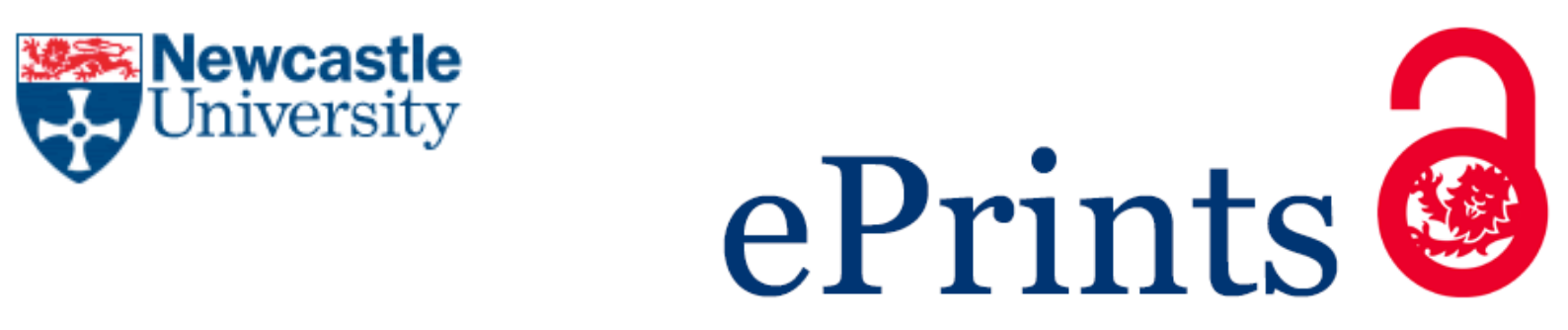

Siller L, Piticharoenphun S, Lemloh M-L, Horrocks BR, Kaulich B, Gianonchelli A, Hunt MRC, Brummer F, Medakovic D. Sulphur-containing compounds as a response in sea urchins exposed to alkylated silicon nanocrystals and $\mathrm{SiO}_{2}$ coated iron oxide nanoparticles. Key Engineering Materials 2016, 672, 312 327.

\title{
Copyright:
}

(C) 2016 by Trans Tech

The publisher permits the right to include the work (post and preprint version) in an institutional repository

DOI link to article:

http://dx.doi.org/10.4028/www.scientific.net/KEM.672.312

Date deposited:

$22 / 02 / 2016$

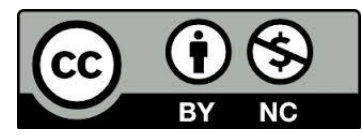

This work is licensed under a Creative Commons Attribution-NonCommercial 3.0 Unported License 


\section{Sulphur-containing compounds as a response in sea urchins exposed to alkylated silicon nanocrystals and $\mathrm{SiO}_{2}$-coated iron oxide nanoparticles}

\section{ŠILLER Lidija, ${ }^{1, a ~ * ~ P I T I C H A R O E N P H U N ~ S u n t h o n, ~}{ }^{2, b}$ LEMLOH Marie- Louise, ${ }^{3,4, \mathrm{c}}$ HORROCKS Benjamin R, ${ }^{5, \mathrm{~d}} \mathrm{KAULICH}$ Burkhard, ${ }^{6, \mathrm{e}}$ GIANONCELLI Alessandra, ${ }^{7, f}$ HUNT Michael R $C^{8,9}$, BRUMMER Franz ${ }^{3, \mathrm{~h}}$ and MEDAKOVIĆ Davorin ${ }^{9, i}$}

${ }^{1}$ School of Chemical Engineering and Advanced Materials, Newcastle University, United Kingdom

${ }^{2}$ Department of Chemical Engineering, Silpakorn University, Thailand

${ }^{3}$ Institute of Biomaterials and Biomolecular Systems, Dept. Zoology, University of Stuttgart

Pfaffenwaldring 57, 70569 Stuttgart, Germany

${ }^{4}$ Present address: INM - Leibniz Institute for New Materials, Campus D2 2, 66123 Saarbrücken,

Germany

${ }^{5}$ School of Chemistry, Newcastle University, United Kingdom

${ }^{6}$ Diamond Light Source, Didcot, United Kingdom

${ }^{7}$ Elettra-Sincrotrone Trieste, TwinMic Beamline, Italy

${ }^{8}$ Centre for Materials Physics, Department of Physics, Durham University, United Kingdom

${ }^{9}$ Center for Marine Research Rovinj, Ruđer Bošković Institute, Rovinj, Croatia

a, ${ }^{*}$ Lidija.Siller@ncl.ac.uk, ${ }^{b}$ sunthon@su.ac.th, ${ }^{c}$ Marie-Louise.Lemloh@inm-gmbh.de, db.r.horrocks@ncl.ac.uk, ${ }^{\mathrm{e}}$ burkhard.kaulich@diamond.ac.uk, ${ }^{\mathrm{f}}$ alessandra.gianoncelli@elettra.eu, ${ }^{9}$ franz.brummer@bio.uni-stuttgart.de, ${ }^{h}$ m.r.c.hunt@durham.ac.uk, ${ }^{i}$ davorin.medakovic@irb.hr

Keywords: sea urchins, toxicity, silicon nanocrystals, iron oxide nanoparticles, fourier transform infrared spectroscopy

Abstract. We report the effects of exposure to alkylated silicon nanocrystals ('alkyl-SiNCs' at concentration $\sim 7.2 \mathrm{mg} / \mathrm{L}$ ) and $\gamma-\mathrm{Fe}_{2} \mathrm{O}_{3}$ nanoparticles coated with ultra-thin silica (' $\mathrm{SiO}_{2}$-coated IONPs' at concentration $\sim 150 \mathrm{mg} / \mathrm{L}$ ) on sea urchins Paracentrotus lividus and Arbacia lixula, respectively, studied with X-ray fluorescence (XRF) and Fourier transform infrared (FTIR) spectroscopies using excitation from a synchrotron light source. A remarkably low mortality and low incidence of skeletal deformation is observed for exposure to both types of nanoparticles studied, despite the high concentrations employed in this work. XRF mapping demonstrates that both types of nanoparticle are found to agglomerate in the body of the sea urchins. FTIR spectra indicates that alkyl-SiNCs remain intact after ingestion and corresponding XRF maps show increased oxygen throughout the organisms, possibly related to oxidation products arising from reactive oxygen species generated in the presence of the nanoparticles. Exposure to $\mathrm{SiO}_{2}$-coated IONPs is found to produce sulphur-containing species, which may be the result of a biological response in order to reduce the toxicity of the nanomaterial. 


\section{Introduction}

The unique properties of nanomaterials have resulted in a significant intensification of their use over the past few years with a commensurate increase in the likelihood of environmental exposure. Nanostructured silicon and iron oxide are particularly important due to their number of current and potential applications. For example, silicon nanocrystals (SiNCs) are promising materials for the manufacturing of electronic devices, and have found use in bio-applications $[1,2]$, while iron oxide nanoparticles (IONPs) have found many biomedical uses [3]. Nanostructured silicon can be found in chemical sensors, biosensors, and luminescent labels for biological imaging [1,2,4] and is attractive due to its biocompatibility, simplicity of surface modification, bright luminescence and good reproducibility. Iron oxide nanoparticles (IONPs) are superparamagnetic and their properties have led to several reports on biomedical uses, such as in diagnostics, controlled drug delivery and separation technologies [5]. IONPs can bind to target cells for labelling and may be used as MRI (magnetic resonance imaging) contrast agents in order to differentiate between healthy and diseased tissues in clinical diagnosis. With specific binding, IONP-bound biomolecules may be separated using a magnetic field [3,6] and IONPs may be employed as drug carriers for site-specific delivery. IONPs can also be used as an agent in hyperthermal cancer treatment in which IONPs embedded in tumours generate heat through application of an alternating magnetic field. This generates temperatures of $41-45^{\circ} \mathrm{C}$, which irreversibly damages cancerous cells but allows healthy cells to recover [7].

The large increase in the use of these two nanomaterials means that it is necessary to understand any potential toxicological effects they might have in the environment if released. Both of these nanomaterials are included in the list of 'representative manufactured nanomaterials for testing on toxicology and risk assessment' by the Organization for Economic Co-operation and Development [8]. Sea urchins are model organisms for assessment of the sea water quality [9], ecology [10], developmental biology [11], embryology, and biomineralization processes [12] and are thus highly appropriate for the study of nanoparticle toxicology. Sea-urchin embryos are often used in toxicological studies: for example, on the effects of UV [13] or X-rays [14]. Therefore, in this work we study the interaction of SiNCs and IONPs with sea urchin embryos belonging to the Mediterranean species Paracentrotus lividus (P. lividus) and Arbacia lixula (A. lixula). X-ray fluorescence (XRF) and Fourier transform infrared spectroscopy (FTIR) using synchrotron radiation excitation were applied to study the interactions.

\subsection{Silicon nanocrystals (SiNCs) and their toxicity}

As SiNCs can be used in biological labelling, the toxicity of SiNCs has been studied for in vitro and in vivo applications. Several published works indicate that SiNCs show low toxicity. Alsharif et al. [15] studied the toxicity of alkyl-capped SiNCs in HeLa cells and freshly isolated primary human skin fibroblasts. They concluded that alkyl-capped SiNCs lack in vitro cellular toxicity by evaluating cell morphology, apoptosis and cell viability assays. A series of cytotoxicity tests of silicon nanoparticles with attached surface molecules on WS1, A549 and HepG2 cells were reported and it was concluded that silicon nanoparticles capped with polar molecules have low toxicity [16]. Cytotoxicity tests of silicon nanoparticles with covalently attached organic monolayers on Caco-2 cells [17,18] and rat alveolar macrophage NR8383 cells [18] suggest a trend in cytotoxicity, depending on the surface charge, i.e., positively charged SiNCs are more cytotoxic than negatively charged SiNPs $[17,18]$.

Durnev et al. [19] performed a study of the toxicity of SiNCs in mice and pregnant rats and showed that DNA damage in the bone marrow cells of mice is considerably increased after $24 \mathrm{~h}$ exposure to SiNC concentrations of $50 \mathrm{mg} / \mathrm{kg}$, compared with $5 \mathrm{mg} / \mathrm{kg}$. After more than $24 \mathrm{~h}$ exposure to $50 \mathrm{mg} / \mathrm{kg} \mathrm{SiNCs,} 60-80 \%$ of the mice used in the experiment were dead. In addition, 
reduced body mass gain in pregnant rats and newborn rats was observed after the injection of a dose of $50 \mathrm{mg} / \mathrm{kg}$ on days 1,7 and 14 of gestation [19]. Moreover, it was found that SiNCs can be accumulated in vivo. Park et al. [20] demonstrated that accumulation of SiNCs occurs in several organs of the mouse after injection. There is no evidence of SiNC toxicity in the mouse after a relatively short period of exposure. They then found that accumulated SiNCs are degraded in vivo and removed from the body within a few days. The low levels of toxicity produced by SiNCs and their biodegradation are useful for clinical translation [20]. The impact of silicon-based quantum dots on the freshwater fish Carassius auratus gibelio [21-23] was also studied recently. The effects of the quantum dots on white muscle, their distribution and their impact on antioxidative stress (GSH) were reported [21]. However, to the best of our knowledge there has been no study of the toxicity of silicon-based nanocrystals to other marine organisms.

\subsection{Iron oxide nanoparticles (IONPs) and their toxicity}

In vitro and in vivo toxicity studies of IONPs have been undertaken by several researchers [24]. In an in vitro study, Karlsson et al. [25] showed that IONPs at $40 \mathrm{mg} / \mathrm{L}$ produce a low level of cytotoxicity in human lung cells. Size differences in the IONPs did not produce a significant difference in their cytotoxicity. However, IONPs can reduce cell proliferation and the viability of murine macrophage cells when concentrations and time exposure increase [26]. Interestingly, IONPs with different surface chemistries show different levels of toxicity. Mahmoudi et al. [27] studied the toxicity of three types of IONPs in HCM cells (isolated from human heart), a neuroblastoma cell line (human bone marrow) and human embryonic kidney cells. IONPs were coated with $-\mathrm{COOH}(\mathrm{IONP}-\mathrm{COOH})$ and $-\mathrm{NH}_{2}\left(\mathrm{IONP}-\mathrm{NH}_{2}\right)$, and compared with bare IONPs. It was found that exposure to positively charged $\mathrm{IONP}-\mathrm{NH}_{2}$ leads to lower cell viabilities than for negatively charged IONP-COOH. Bare IONPs were found to display higher toxicity than those of both coated IONPs. In an in vivo study, Szalay et al. [28] studied the toxicity of IONPs in adult male wistar rats. Pathological examination indicated a weak pulmonary fibrosis at the lungs of the exposed rat. High doses of IONPs showed higher levels of pulmonary fibrosis than lower doses [28]. Gu et al. [29] demonstrated that the accumulation of IONPs was observed mainly in the liver and spleen of mice. No significant tissue damage and no obvious losses of body weight have been observed in the mice.

Toxicity assessments of iron oxide nanoparticles have been made for freshwater zebrafish (Danio rerio) embryos [30], demonstrating that at a IONP concentration of $10 \mathrm{mg} / \mathrm{L}$ the nanoparticles instigate developmental toxicity causing mortality, hatching delay and malformations [30]. For marine organisms, the uptake and biological response to $\mathrm{Fe}_{2} \mathrm{O}_{3}$ nanoparticles in excised gills and blood cells of the edible mussel Mytilus sp [31] and Mytilus galloprovincialis [32] have been previously studied. It was reported that at the $\mathrm{pH}$ of natural seawater nano-Fe particles aggregate into large polydispersed and porous particles with no biological impact for Mytilus galloprovincialis [32].

There is little work addressing the toxicity of iron ions in sea urchins. The "no observed effect concentration' (NOEC) of iron is $0.21 \mathrm{mg} / \mathrm{L}$, which allows normal development of sea urchin larvae [33]. However, higher concentrations of iron induce abnormal development. Pagano et al. [34] carried out an experiment to test the toxicity of iron ions in sea urchins ( $P$. lividus), using $\mathrm{FeCl}_{3}$ as $\mathrm{Fe}(\mathrm{III})$ source. $\mathrm{Fe}(\mathrm{III})$ concentrations at or above $0.055845 \mathrm{mg} / \mathrm{L}$ significantly increased the number of malformations in P. lividus embryos. One study, by Falugi et al. [35], investigated the toxicity of IONPs $\left(\mathrm{Fe}_{3} \mathrm{O}_{4}\right)$ in immune cells of adult sea urchins (P. lividus). The results showed that none of the adult sea urchins survived after 2 days of exposure to a IONP concentration of $10 \mathrm{mg} / \mathrm{L}$. However, at the lower concentration of $0.1 \mathrm{mg} / \mathrm{L}$, sea urchins can live for 5 days without major signs of a pathological state. 
In the work reported here we employ silicon nanocrystals capped with undecane (alkylSiNCs) which are synthesized following the method of Lie et al. [36]. When considering which iron oxides to use we recognise that this material can exist in several forms such as $\mathrm{FeO}$ (wustite), $\mathrm{Fe}_{3} \mathrm{O}_{4}$ (magnetite), $\alpha-\mathrm{Fe}_{2} \mathrm{O}_{3}$ (hematite), $\beta-\mathrm{Fe}_{2} \mathrm{O}_{3}, \varepsilon-\mathrm{Fe}_{2} \mathrm{O}_{3}$ and $\gamma-\mathrm{Fe}_{2} \mathrm{O}_{3}$ (maghemite) [37]. The $\mathrm{Fe}_{3} \mathrm{O}_{4}$ (magnetite) and $\gamma-\mathrm{Fe}_{2} \mathrm{O}_{3}$ (maghemite) are favoured for use because their biocompatibility has already been confirmed [38]. In this work, the IONPs used are $\gamma-\mathrm{Fe}_{2} \mathrm{O}_{3}$ (maghemite) and are coated with a silica layer [39], and are termed silica-coated iron oxide nanoparticles $\left(\mathrm{SiO}_{2}\right.$-coated IONPs).

\subsection{Synthesis and characterisation of alkylated SiNCs}

The galvanostatic anodization method employed by Lie et al. [36] was used to synthesize the alkyl-SiNCs employed in this study, with a minor modification to the refluxing time and current density. A silicon sample (approx $1 \times 1 \mathrm{~cm}^{2}$ in area and $525 \pm 50 \mu \mathrm{m}$ thick, boron-doped p-Si $<100>$, $10 \Omega . c m$ resistivity, Compart Technology, Peterborough, UK) was placed in an electrochemical cell and etched using $2 \mathrm{ml}$ of $1: 1 \mathrm{v} / \mathrm{v}$ solution of $48 \%$ aqueous $\mathrm{HF}$ and ethanol solution to form porous silicon. A layer of luminescent porous silicon was produced by passing a current of $400 \mathrm{~mA}$ through the cell for five minutes. SiNCs were extracted from the porous silicon via a thermal hydrosilation reaction producing undecane-capped nanocrystals. Alkyl-SiNCs suspended in dichloromethane (DCM) were obtained from 16 porous silicon samples. The alkyl-SiNCs suspensions from each batch were mixed together and excess DCM evaporated at a low heat until the volume of the resulting suspension was reduced to $15 \mathrm{~mL}$. It is estimated that one sample of porous silicon provided $0.1 \mathrm{mg}$ alkylated SiNCs [40]. Therefore, the concentration of alkylated SiNCs was approximately $72 \mathrm{mg} / \mathrm{L}$. A 1:10 dilution was applied, reducing the concentration to 7.2 $\mathrm{mg} / \mathrm{L}$ for use in this study.

Alkyl-SiNCs, synthesized by this method [36] have been well characterized elsewhere [4144] and their properties found to be reproducible. Alkyl-SiNCs produced in this way have been found to have a diameter of $1.8 \pm 0.34 \mathrm{~nm}$ [42]. In fluorescence spectroscopy, alkyl-SiNCs in a trichloromethane dispersion only show emission peaks at $670 \mathrm{~nm}$, using 280, 330, 350 and $390 \mathrm{~nm}$ excitation sources. In addition, there are several infrared (IR) bands found. Those at 1259 and $800 \mathrm{~cm}^{-1}$ are assigned to $\mathrm{Si}-\mathrm{CH}_{2}-\mathrm{R}$ deformation and minority silanol sites. With the gradual oxidation of alkylated SiNCs, two broad IR peaks are found to occur at $1050 \mathrm{~cm}^{-1}$ (Si-O-Si, asymmetric and symmetric stretching modes) and at $700-900 \mathrm{~cm}^{-1}$ (Si-O bending modes). Methylene C-H stretching peaks occur at 2854 and $2926 \mathrm{~cm}^{-1}$, and a terminal $\mathrm{CH}_{3}$ stretching mode appears at $2956 \mathrm{~cm}^{-1}$. Both of these bands confirm the presence of long alkyl chains in the alkylSiNCs [36].

\subsection{Synthesis of silica-coated iron oxide nanoparticles $\left(\mathrm{SiO}_{2}\right.$-coated IONPs)}

Silica-coated iron oxide nanoparticles $\left(\mathrm{SiO}_{2}\right.$-coated IONPs) were obtained from the Department for Materials Synthesis, Josef Stefan Institute, Slovenia. The synthesis methods followed were those outlined in Ref. 39. Iron oxide nanoparticles with silica coatings are synthesized through precipitation in aqueous solutions. Solutions containing $\mathrm{Fe}^{2+}$ (from $\mathrm{FeSO}_{4}$ ) and $\mathrm{Fe}^{3+}$ ions (from $\mathrm{Fe}_{2}\left(\mathrm{SO}_{4}\right)_{3}$ ) were precipitated with concentrated ammonia solution $(25 \%)$ in two steps. First, the $\mathrm{pH}$ of the solution was adjusted to value of 3 , which was maintained for 30 minutes. Second, the $\mathrm{pH}$ value was subsequently increased to 11.6 with oxygen from the air. The nanoparticles synthesized by this process were then washed with dilute ammonia solution at $\mathrm{pH}$ 10.5. $5 \mathrm{~mL}$ of citric acid $(500 \mathrm{mg} / \mathrm{L})$ was mixed with the suspension of washed nanoparticles (approximately $2 \mathrm{~g}$ of particles in $20 \mathrm{~mL}$ of water) and stirred vigorously. The $\mathrm{pH}$ of the solution was adjusted to 5.2 with concentrated ammonia solution and then heated to $80^{\circ} \mathrm{C}$. After the solution was cooled down to room temperature, the agglomerated particles were removed from the solution 
by centrifuge. Finally, the nanoparticles were coated with a silica layer by hydrolysis and the polycondensation of tetraethyl orthosilicate (TEOS), with the use of an alkaline catalyst $\left(\mathrm{NH}_{3}\right.$ or $\mathrm{KOH})$.

The method described above produces $\gamma-\mathrm{Fe}_{2} \mathrm{O}_{3}$ nanoparticles coated with an ultra-thin layer of silica [39]. The silica layer helps to improve the surface reactivity of IONPs. The diameter of these $\mathrm{SiO}_{2}$-coated IONPs is $\sim 13 \mathrm{~nm}$. The coating process creates a relatively homogeneous amorphous layer of Si 1-2nm thick which is clearly visible on the surfaces of IONPs [39], as seen in the transmission electron microscopy (TEM) images of Figure 1. Kralj et al. [45] reported that $\mathrm{SiO}_{2}$-coated IONPs show a strong IR band at $650-560 \mathrm{~cm}^{-1}$, assigned to $\mathrm{Fe}-\mathrm{O}$ vibrations and at around $1030 \mathrm{~cm}^{-1}$ which correspond to the $\mathrm{Si}-\mathrm{OH}$ or Si-O-Fe stretching vibrations. In addition, an asymmetric Si-O-Si vibration between 1130 and $990 \mathrm{~cm}^{-1}$ is also observed [45]. The concentration of synthesized silica-coated IONPs obtained is $15,000 \mathrm{mg} / \mathrm{L}$ (or equivalent to $1.5 \mathrm{wt} \%$ ). The $\mathrm{SiO}_{2^{-}}$ coated IONPs were diluted to the ratio of 1:100 before exposure to the sea urchins.
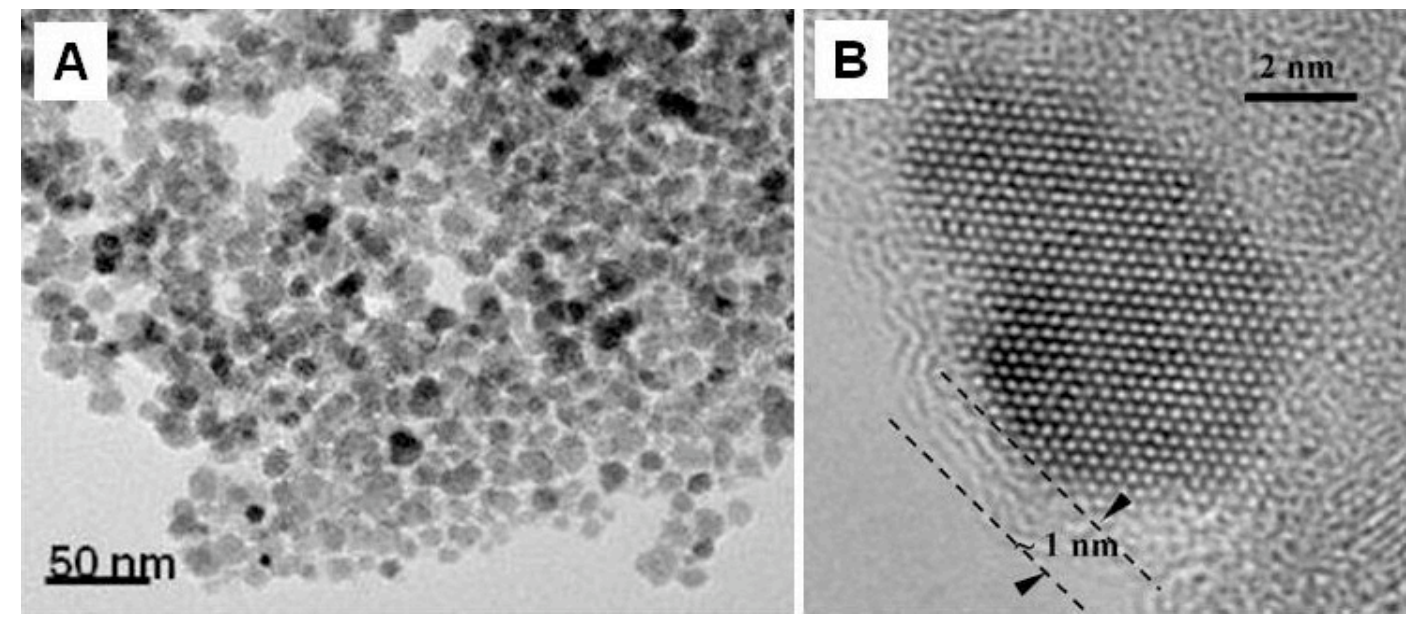

Figure 1. (A) TEM images of $\gamma-\mathrm{Fe}_{2} \mathrm{O}_{3}$ nanoparticles (IONPS) coated with a silica layer, synthesized by the method from Kralj et al. [39].(B) TEM images of silica layer on the IONPs.

\subsection{Sea urchin fertilization}

Adult sea urchins ( $P$. lividus, A. lixula) were taken from the Croatian coast of the Adriatic Sea by scuba diving. Gamete (sperm and egg) production was induced by injecting $0.5 \mathrm{M} \mathrm{KCl}$ into the adult sea urchins. The gametes were collected and pooled in $0.22 \mu \mathrm{m}$ filtered natural sea water (FNSW) in which fertilization was also carried out. Two hours after fertilization, the sea urchin embryos developed into the 4 cell stage. At this point they were washed in a $40 \mu \mathrm{m}$ filter using FNSW. After washing, the sea urchin embryos were transferred to 1 multiwall-plates which contained FNSW and were divided into control and 'exposed' samples. The temperature during fertilization was between 18 and $19^{\circ} \mathrm{C}$.

The 'exposed' samples of P. lividus were exposed to $7.2 \mathrm{mg} / \mathrm{L}$ of alkylated SiNCs whereas A. lixula was used for exposure to the $150 \mathrm{mg} / \mathrm{L}$ silica-coated iron oxide nanoparticles $\left(\mathrm{SiO}_{2}\right.$-coated IONPs). The control and exposed sea urchin larvae were collected $51 \mathrm{~h}$ after fertilization for the $P$. lividus samples and at $48 \mathrm{~h}$ for A. lixula. The larvae were fixed with ethanol and washed with distilled water before measurements were undertaken. 


\subsection{Measurement techniques}

X-ray fluorescence (XRF) was used to detect the presence of alkyl-SiNCs and $\mathrm{SiO}_{2}$-coated IONPs and chemical changes in the sea urchins measured using the Fourier transform infrared (FTIR) spectroscopy. The measurements were performed at the TwinMic and SISSI beamlines of the ELETTRA synchrotron light source (Trieste, Italy). Both control and exposed samples of sea urchin larvae were washed with distilled water several times in preparation for measurements using both XRF and FTIR. Washed sea urchin larvae were placed on a gold grid with polycarbonate film for XRF measurement or a $0.2 \mathrm{~mm} \mathrm{BaF}$ window for FTIR. All samples were dried at room temperature before the measurements were taken.

The TwinMic X-ray spectromicroscope operates with beam energy in the range of 0.4-2.2 keV, and a photon flux of $10^{11}-10^{12}$ photons $/ \mathrm{s}$ [46]. Therefore, $K$ and $M$-edges of light elements from phosphorus to boron (including silicon and iron) can be detected by X-ray fluorescence (XRF). A monochromatized beam is focused by a zone plate (ZP), forming a microprobe across which the specimen is raster-scanned. The transmission signal is detected by a fast readout electron-multiplying charged couple device (CCD, iXon CV860-BV, Andor Technology), connected to a phosphor screen-based visible light converting system. In fluorescence mode, the fluorescence emission was detected by eight silicon drift detectors in an annular backscattering configuration around the specimen [47]. The scanned area was chosen in the range of 60$80 \mu \mathrm{m}$ with a pixel range of 60-100 in both the $\mathrm{X}$ and $\mathrm{Y}$ directions.

The endstation on the SISSI beamline is equipped with a FTIR spectrometer (Bruker VERTEX 70), coupled to a microscope (Bruker Hyperion 3000). The FTIR spectrometer operated in transmission mode between 850 and $4000 \mathrm{~cm}^{-1}$, with a resolution of $4 \mathrm{~cm}^{-1}$ and a beam footprint of $10 \mu \mathrm{m} \times 10 \mu \mathrm{m}$. The scan step was $5 \mu \mathrm{m}$ in both directions. The transmission signals were accumulated for 256 scans for the alkylated SiNC-treated sea urchins and 512 scans for $\mathrm{SiO}_{2}$-coated IONP-exposed sea urchin at each pixel. Background spectra were collected every 30 minutes.

\section{Results and discussion}

\subsection{Interaction of alkylated silicon nanocrystals (alkylated SiNCs) with exposed sea urchins}

X-ray fluorescence (XRF) was used to detect the presence of alkylated-SiNCs in sea urchins at $51 \mathrm{~h}$ after fertilization. Data obtained from XRF measurements were analysed using the 'PyMca' software [48] to create elemental maps over the sea urchin. Figure 2 presents data from a typical sea urchin from the control sample (left column) and two regions - the anterior (or top) part (middle column) and posterior (middle bottom) part (rightmost column) - from a typical sea urchin exposed to alkylated SiNCs. The topmost figures in each column (Figs. 2A, B, and C) are optical microscopy images showing the sea urchins with the superimposed boxes indicating the regions over which XRF data in the column below were obtained. The second row of Figure 2 (sub-figures $\mathrm{D}, \mathrm{E}$ and F) present scanning transmission X-ray microscopy (STXM) images derived from the absorption of the incident X-ray beam. An area of $65 \times 60 \mu \mathrm{m}^{2}$ was examined on the control organism (Figure 2D) with the anterior and posterior regions of the alkylated-SiNC exposed sea urchin measured over scanned areas of $80 \times 79 \mu \mathrm{m}^{2}$ (Figure 2E) and $40 \times 80 \mu \mathrm{m}^{2}$ (Figure 2F), respectively.

As seen from the Silicon $K$ edge XRF map shown in Figure $2 \mathrm{G}$, Si was observed in the control sea urchin, on the skeleton, and distributed over the specimen. Si is an essential element for normal development in biological systems [49] and it is present within the filtered natural sea water. After alkylated SiNC-exposure, $\mathrm{Si}$ was also observed in the anterior and posterior regions of the alkylated-SiNC exposed sea urchin. The anterior region (Figure 2H) shows a greater $\mathrm{Si}$ 
concentration than that present in the control sample. Si was especially concentrated around the oral region of the nanoparticle exposed sea urchin larvae, which is the most probable entry route into the organism. The posterior (Figure 2I) of the sea urchin shows a considerably greater concentration of silicon (note the difference in the false colour scale of this image in comparison with that in Figures $2 \mathrm{G}$ and $2 \mathrm{H}$ ). Moreover, there is a clear 'hot spot' within the image which indicates an agglomeration of alkylated-SiNCs inside sea urchin larvae, possibly incorporated through the mouth. Therefore, we suggest that there is a preferential agglomeration and concentration of the alkylated Si-NCs within the sea urchin.

Figures 2J, K and L, present $\mathrm{O} K$-edge XRF maps. It can be seen in both the anterior and posterior region of the nanoparticle-exposed sea urchins that oxygen is distributed over both the skeleton and body, while it is observed primarily in the skeleton of the control sea urchin. Given that the sea urchin skeleton is composed of $\mathrm{CaCO}_{3}$ (calcite) containing about $5 \% \mathrm{Mg}$ [50] we would expect a strong $\mathrm{O} K$-edge signal primarily from the skeletal region. A possible explanation for the much higher 'background' oxygen concentration throughout the nanocrystal exposed sea urchin is the presence of reactive oxygen species (ROS), the production of which has previously been proposed to be one of the effects of nanomaterial toxicity [51,52]. Fujioka et al. [53] have confirmed that silicon nanocrystals are able to produce oxygen radicals in solution, detected via luminol reaction. These oxygen radicals lead to the presence of peroxy radicals in co-cultured cells [53]. Non-treated porous silicon microparticles were also found to generate reactive oxygen species (ROS) by Low and co-workers [54], which interacted with the components of the cell culture medium and resulted in the formation of cytotoxic species. It is therefore reasonable to infer ROS may be generated as the result of toxicity of the silicon nanocrystals used. Since the lifetime of ROS is typically very short, the observed increase in oxygen signal in the nanocrystal exposed organisms is likely to be due to the oxidation products which derive from reactions of ROS with organic material. It is notable that despite the increase in oxidation products there is a distinct lack of deformation and mortality in these specimens.

Figure 3A shows an optical image of a typical sea urchin exposed to alkylated-SiNCs from the same sample as those examined by XRF. The two yellow boxes indicate the areas over which spectra were obtained. The spectra were summed and averaged, the results of which are displayed in Figure 3B (black spectrum) along with spectra from a typical control organism, AgNP-exposed sea urchins from our previous work [55] and reference spectra of calcite (blue), sodium sulphate (red) and sodium thiosulphate (green). A series of overlapping infra-red (IR) peaks between $\sim 850$ and $\sim 1650 \mathrm{~cm}^{-1}$ is seen in all the sea urchins studied, but with significantly different relative intensities between the organisms studied. The peaks at 868 and $1398 \mathrm{~cm}^{-1}$ in the alkylated-SiNC exposed sea urchins may be assigned to Mg-containing calcite [56] by comparison with the calcite reference spectrum (Figure 3B, blue spectrum) which displays IR peaks at 864 and $1390 \mathrm{~cm}^{-1}$. A similar assignment can be made in the spectra for the control and AgNP-exposed sea urchins.

Examination of the higher wavenumber region of the FTIR spectra presented in Figure 3B shows a striking difference between the spectrum of the alkylated-SiNC sea urchin sample and both the control and AgNP exposed organism between $\sim 2750$ and $\sim 3750 \mathrm{~cm}^{-1}$. In order to understand this variation it is necessary to consider the IR-active modes of the as-synthesised alkylated-SiNCs, which show IR peaks at $2956 \mathrm{~cm}^{-1}$, assigned to the terminal $\mathrm{CH}_{3}$ stretching mode of the alkyl chain, and at 2926 and $2854 \mathrm{~cm}^{-1}$, which are assigned to methylene C-H stretching [36]. These three peaks are associated with the monolayer of undecane species bound to the nanocrystal surface [36]. As seen in Figure 3B, these three peaks are also observed in alkyl-SiNC exposed sea urchin at 2957, 2926 and $2854 \mathrm{~cm}^{-1}$ and indicate the presence of alkyl chains in sea urchins. Whilst such chains could also be associated with lipids or other normal cell molecules, they are clearly considerably more intense in the alkyl-SiNC exposed sea urchin than in either the control or AgNP exposed species. This observation, when combined with the XRF elemental maps discussed above, provide strong support for the hypothesis that alkyl-SiNCs are indeed present in sea urchin intact. Further evidence is provided by the broad FTIR peak at $1050 \mathrm{~cm}^{-1}$ observed in the alkyl-SiNC-exposed sea urchin which can be assigned to Si-O-Si antisymmetric and symmetric stretches also observed in as- 


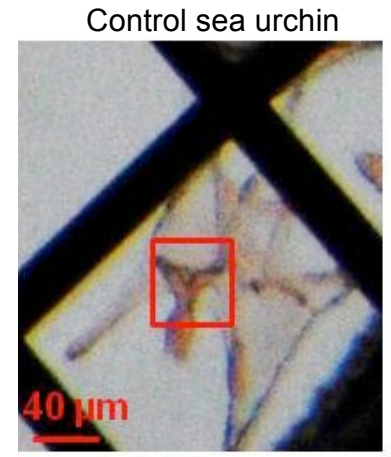

(A)

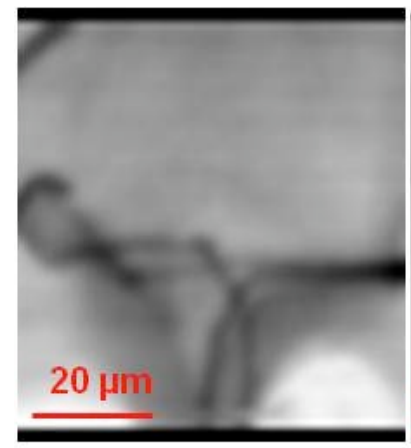

(D)

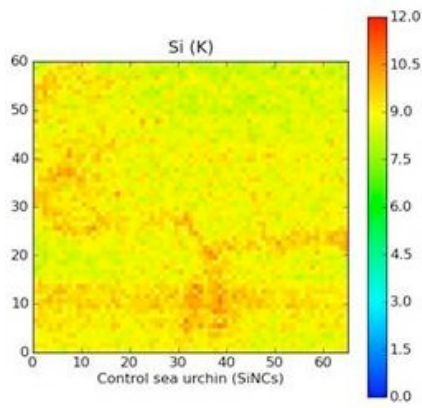

(G)

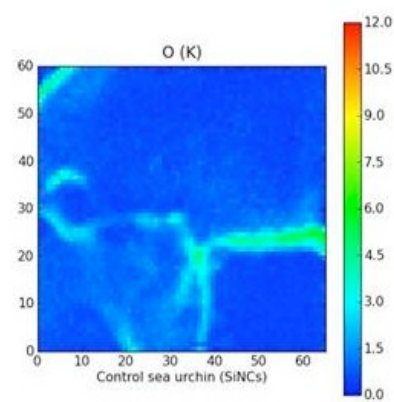

(J)
SiNC-exposed sea urchin-anterior

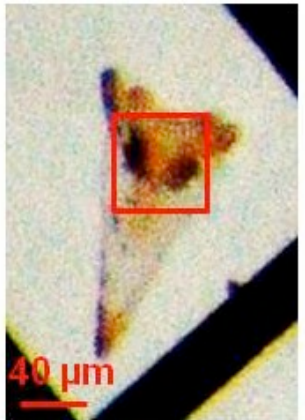

(B)

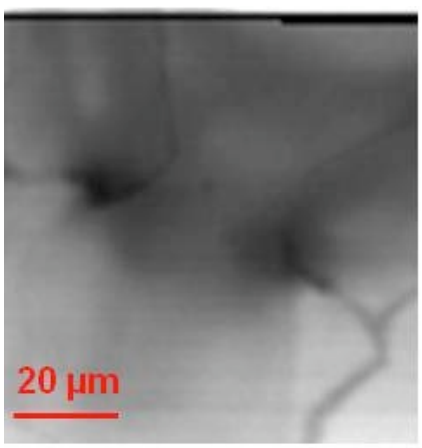

(E)

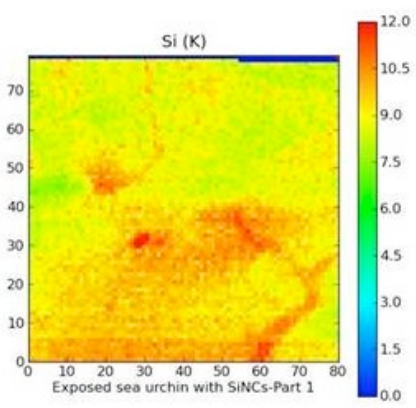

(H)

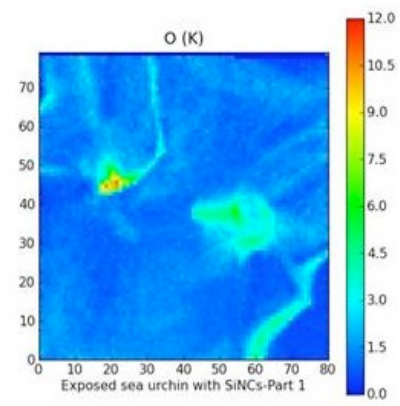

(K)
SiNC-exposed sea urchin-posterior

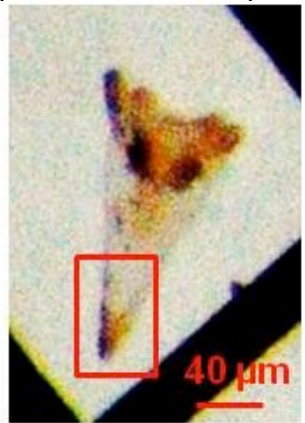

(C)

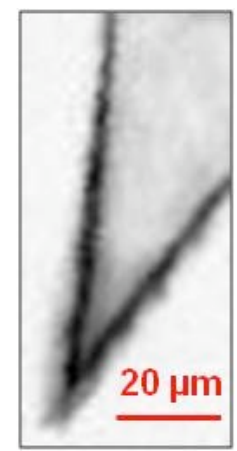

(F)

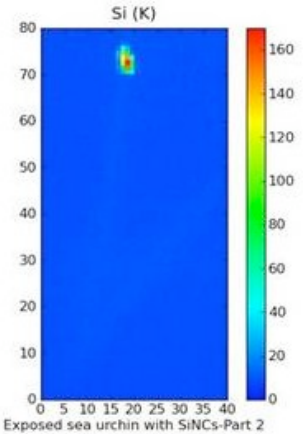

(I)

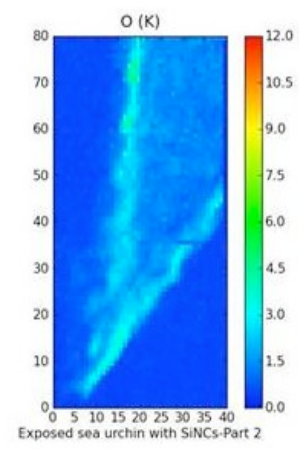

(L)

Figure 2. Optical micrographs, STXM and XRF maps of a P. lividus control and a specimen exposed alkyl-SiNCs. The left column presents the control sea urchin. The sea urchin samples were collected at 51 h after fertilization. See text for details. 

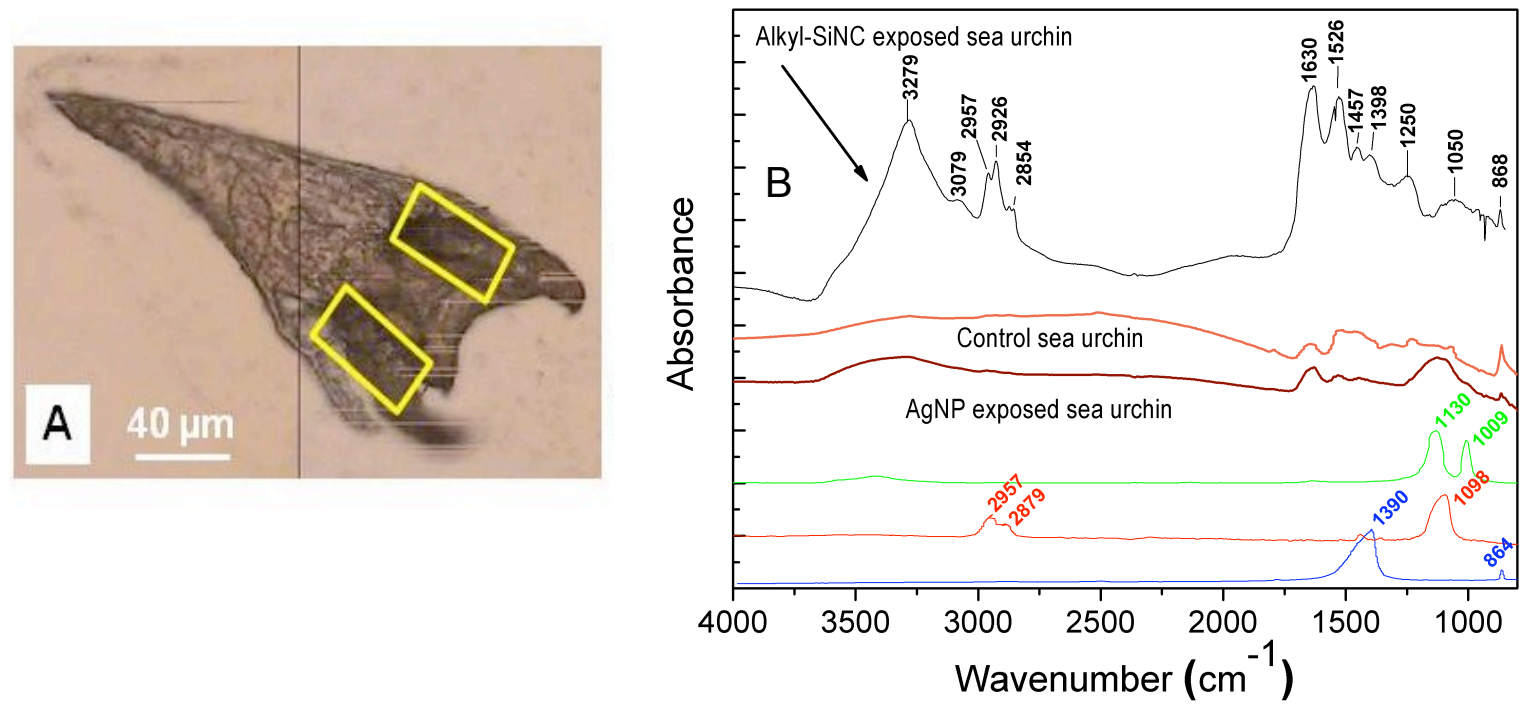

Figure 3. (A) A sea urchin (P. lividus) exposed to alkyl-SiNCs collected at 51 h after fertilization. The yellow boxes indicate the regions from which FTIR spectra were obtained. (B) FTIR spectra from alkylated SiNC-exposed sea urchin (black), control sea urchin (orange) [55], AgNP-exposed sea urchin (brown) at $51 \mathrm{~h}$ after fertilization with $0.3 \mathrm{mg} / \mathrm{L} \mathrm{AgNPs} \mathrm{[55],} \mathrm{calcite} \mathrm{(blue),} \mathrm{sodium}$ sulphate (red) and sodium thiosulphate (green).

synthesized alkyl-SiNCs [36]. Sulphur-containing compounds, as seen in AgNP exposed sea urchins [55,57-59], are not obviously present in the alkyl-SiNC exposed sea urchin, suggesting a toxicological response strongly dependent on nanoparticle composition.

Alkyl-SiNCs also possess an IR-active mode at $1259 \mathrm{~cm}^{-1}$ which is assigned to the $\mathrm{Si}-\mathrm{CH}_{2}-\mathrm{R}$ deformation [36]. In the spectrum from the alkyl-SiNC exposed sea urchin (Figure 3B), this peak may overlap with several peaks of organic compounds such as amino acids, such as histidine [60] and membrane lipids [61]. Histidine (His) and tyrosine (Tyr) are amino acids found in sea urchin larvae [62], while lipids form membranes within the organism [61]. IR peaks at 1630 and $1457 \mathrm{~cm}^{-1}$ can be assigned to membrane lipids $\left(\delta_{a s}\left(\mathrm{NH}_{3}^{+}\right)\right.$at $1630 \mathrm{~cm}^{-1}$ and $\delta_{a s}\left(\mathrm{CH}_{3}\right)$ at $1460 \mathrm{~cm}^{-1}$ [61]), while the IR peak at $1526 \mathrm{~cm}^{-1}$ can be attributed to an amino acid, Lysine (Lys, $\delta_{s}\left(N H_{3}^{+}\right)$at 1526$1527 \mathrm{~cm}^{-1}$ ) [60]. The difference in relative strengths of the IR modes associated with these species between the alkyl-SiNC exposed and the control and AgNP exposed organisms originates from the regions over which the spectra were acquired. The scan area producing the spectra from the latter were primarily from skeletal regions, whilst that for the former (shown in Figure 3A) incorporated a wider region of the sea urchin. This difference in scan region is also reflected in the much larger intensity of the $v_{s}(O-H)$ mode of water at $3279 \mathrm{~cm}^{-1}$.

\subsection{Interaction of $\mathrm{SiO}_{2}$-coated IONPs with sea urchins}

XRF was used to detect $\mathrm{SiO}_{2}$-coated IONPs in exposed sea urchins (A. lixula), $48 \mathrm{~h}$ after fertilization, in a similar manner to that described for the alkyl-SiNC exposed organisms described above. In Figure 4, the left column contains data from the control sea urchins, while the middle and right column represent $\mathrm{SiO}_{2}$-coated IONP exposed sea urchins examined in two different regions 
(labelled 'Region 1' and 'Region 2'). The topmost images in each column (Figures 4 A, B and C) present optical micrographs of the sea urchins. The superimposed boxes indicate the regions in which STXM and XRF mapping were undertaken. STXM images are presented in Figures 4 D, E and $\mathrm{F}$ for the control and $\mathrm{SiO}_{2}$-coated IONP exposed sea urchins respectively. In Figure 4D the yellow dotted lines outline an area $80 \times 33 \mu \mathrm{m}^{2}$ over which subsequent XRF mapping of the control sample was performed. Figure 4B and C, cover a scanned area of $80 \times 80$ and $80 \times 60 \mu \mathrm{m}^{2}$ respectively and XRF maps were obtained over the complete region of the image.

Figure 4G shows an XRF intensity map obtained at the Fe $L$ edge and demonstrates that iron can be observed throughout the body of the control sample. This is to be expected, as Fe is used e.g., in the electron transfer process in biological systems [63]. After exposure to $\mathrm{SiO}_{2}$-coated IONPs, Figure $4 \mathrm{H}$ and I, there is a significant increase in Fe signal (note the difference in intensity scale with that of Figure $4 \mathrm{G}$ ) with 'hot spots' present, close to the oral region. These localised regions of significant $\mathrm{Fe}$ intensity are indicative of the agglomeration of the $\mathrm{SiO}_{2}$-coated IONPs within the organism. Unlike the sea urchins exposed to alkyl-SiNCs, those exposed to $\mathrm{SiO}_{2}$-coated IONPs do not show a significant difference in $\mathrm{O} K$ edge XRF intensity to the control sea urchin, as can be seen in Figures $4 \mathrm{~J}, \mathrm{~K}$ and $\mathrm{L}$, suggesting a rather different response of the sea urchins to the two nanoparticle types.

FTIR spectra were obtained from a $\mathrm{SiO}_{2}$-coated IONP-exposed sea urchin A. lixula over the regions indicated by the boxes in the optical micrograph shown in Figure 5A. The scanned area is divided into two regions, which are labelled 'Part A' and 'Part B' with the FTIR spectra presented in Figure 5B (black and green curves, respectively). As in Figure 3, FTIR spectra of both the control and AgNP-exposed sea urchins from previously reported work [55] are shown along with reference spectra. The FTIR spectrum associated with Part A of the $\mathrm{SiO}_{2}$-coated IONP exposed sea urchin shows a well-defined peak at $863 \mathrm{~cm}^{-1}$, which is assigned to $\mathrm{Mg}$ containing calcite. This feature is absent from the spectrum originating from Part B, indicating that the former is associated with a region with a much higher skeletal content than the latter.

A broad intensity maximum is seen between 890 and $1320 \mathrm{~cm}^{-1}$ in the spectrum from Part A of the $\mathrm{SiO}_{2}$-coated IONP exposed sea urchin, with peaks/shoulders visible at 1130, 1074, and $990 \mathrm{~cm}^{-1}$. As-synthesised $\mathrm{SiO}_{2}$-coated IONPs show an IR band at $1030 \mathrm{~cm}^{-1}$ (assigned to the $\mathrm{Si}-\mathrm{OH}$ or Si-O-Fe stretching vibrations of the silica shell) and between 990 and $1130 \mathrm{~cm}^{-1}$ which corresponds to the asymmetric Si-O-Si vibration [45]. Hence, given the observation of nanoparticle agglomeration evidenced by the XRF maps of Figure 4, we can conclude that there may be a contribution to the IR spectra of the sea urchins from the nanoparticles in this region. More conclusive evidence for the contribution of the $\mathrm{SiO}_{2}$-coated IONPs is provided by the peak at $1648 \mathrm{~cm}^{-1}$ in spectra obtained from both Part A and B of the nanoparticle exposed sea urchin, Figure 5B (black and green spectra, respectively). This peak is observed in the as-synthesized $\mathrm{SiO}_{2}-$ coated IONPs at $1650 \mathrm{~cm}^{-1}$ and is attributed to amine bonds [45].

Sulphur plays a major role in biological response to reduce toxicity [55,57-59] and there is evidence for the presence of sulphur-containing species in the spectra of the $\mathrm{SiO}_{2}$-coated IONP sea urchins in Figure 5B. A maximum of intensity is observed at $1130 \mathrm{~cm}^{-1}$, in the spectrum from Part A (and from the AgNP-exposed sea urchin sample [55]), which corresponds well with the reference spectrum from sodium thiosulfate (green spectrum). Other FTIR peaks of sulphur-containing compounds, at 2957 and $2877 \mathrm{~cm}^{-1}$, can be seen in the spectra from both Parts A and B. This observation indicates the availability of sulphur-containing compounds used in the reduction of toxicity, caused by exposure to $\mathrm{SiO}_{2}$-coated IONPs.

The FTIR peaks which are observed between 1600 and $1320 \mathrm{~cm}^{-1}$ in both the spectra from Parts $\mathrm{A}$ and $\mathrm{B}$ of the to $\mathrm{SiO}_{2}$-coated IONP exposed organism can be associated with amino acids 


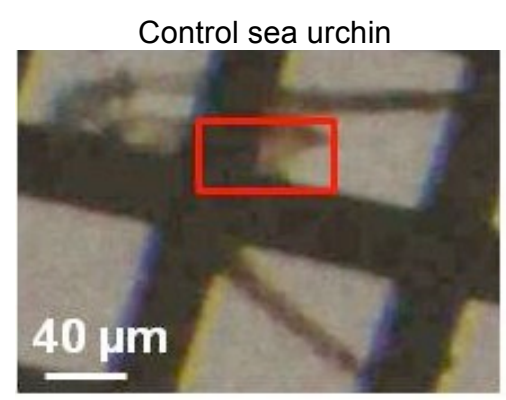

(A)

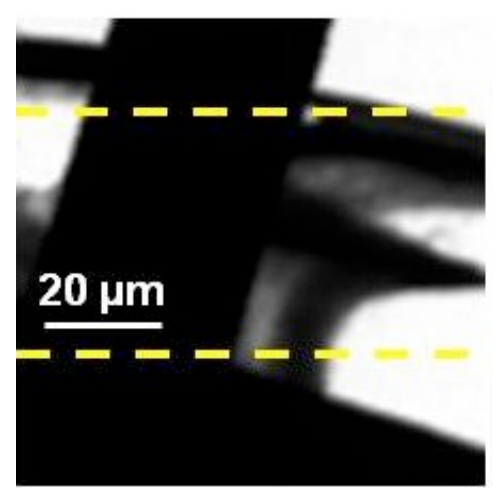

(D)

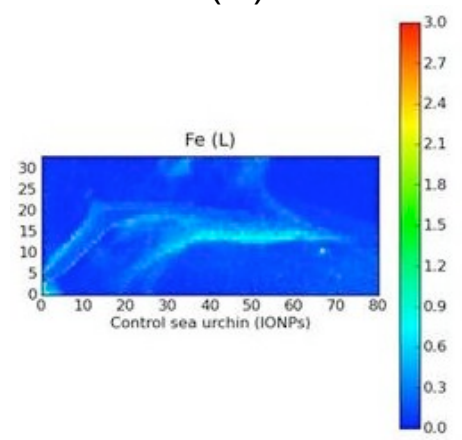

(G)

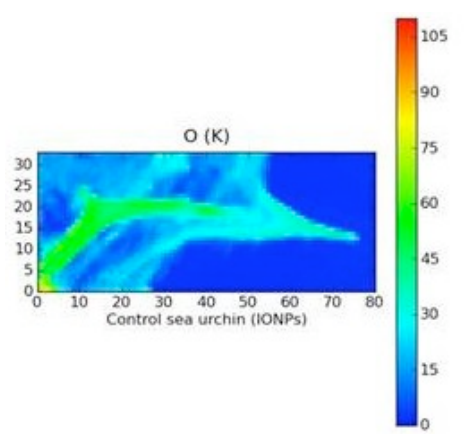

(J)

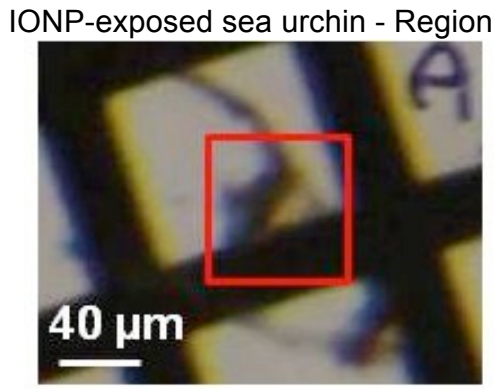

(B)

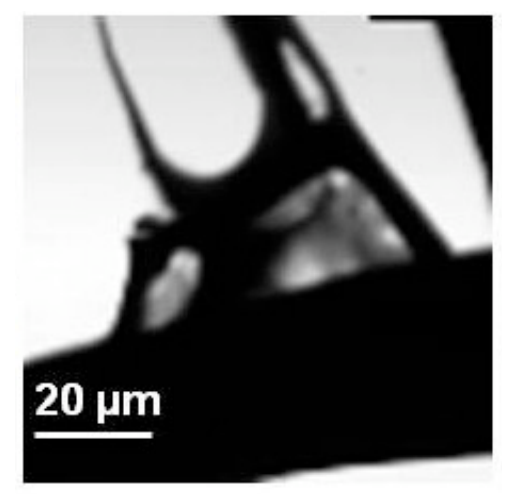

(E)

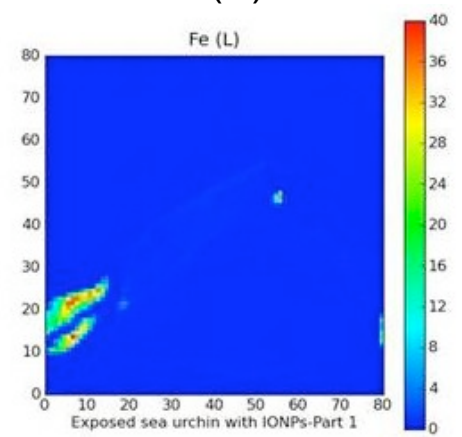

(H)

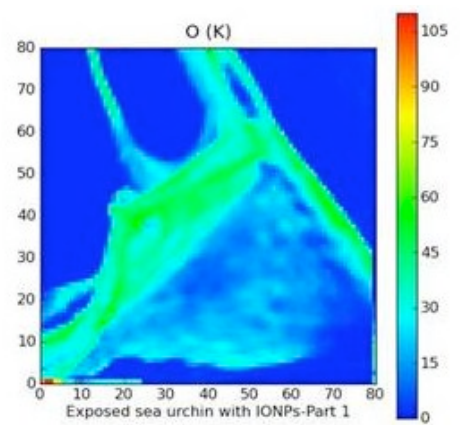

(K)
IONP-exposed sea urchin - Region 2

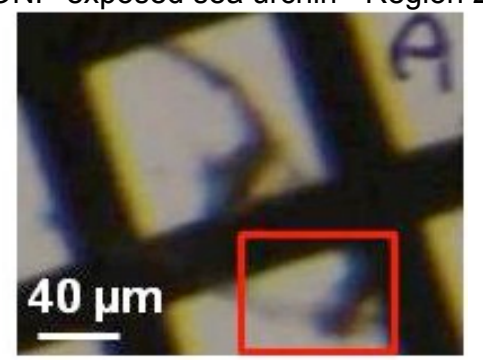

(C)

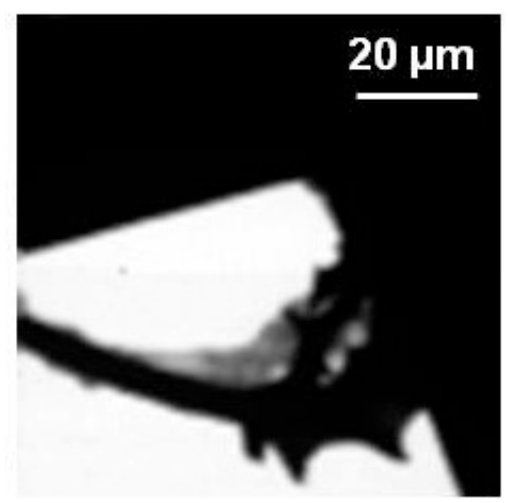

(F)

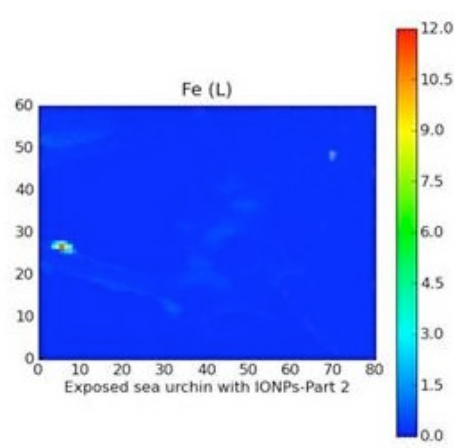

(I)

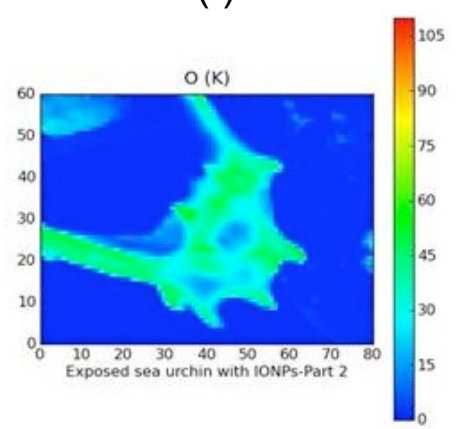

(L)

Figure 4. Optical micrographs, STXM and XRF maps a control and $\mathrm{SiO}_{2}$-coated IONP exposed sea urchin (A. lixula). The sea urchin samples were collected at $48 \mathrm{~h}$ after fertilization. The left column presents the control sea urchin. The middle column presents $\mathrm{SiO}_{2}$-coated IONP-exposed sea over Region 1. The right column presents $\mathrm{SiO}_{2}$-coated IONP-exposed sea urchin over Region 2. See text for details. 

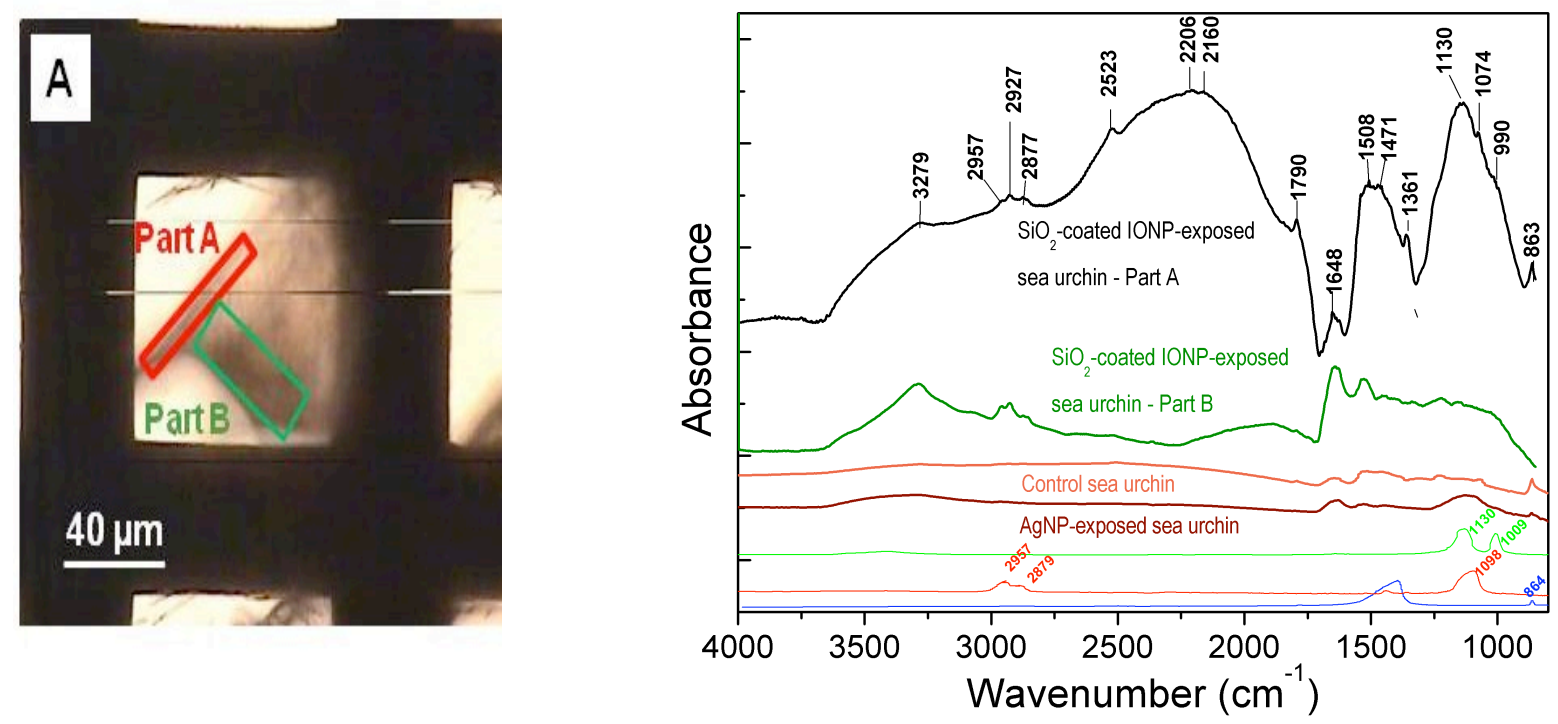

Figure 5. (A) Optical micrograph of a sea urchin (A. lixula) exposed to $\mathrm{SiO}_{2}$-coated IONPs. The sea urchin sample was collected at $48 \mathrm{~h}$ after fertilization. (B) FTIR spectra from the $\mathrm{SiO}_{2}$-coated IONP exposed sea urchin (black) over the area in the red rectangle from (A) and over the area of the green rectangle, control sea urchin (P. lividus) (orange) [55], AgNP-exposed sea urchin (brown) at $51 \mathrm{~h}$ after fertilization with $0.3 \mathrm{mg} / \mathrm{L}$ AgNPs [55], calcite (blue), sodium sulphate (red) and sodium thiosulfate (light green).

found in eggs and larvae of sea urchins $[62,64,65]$, as discussed above. The much broader, multi-component, peak between 2500 and $2000 \mathrm{~cm}^{-1}$ strongly visible in the spectrum from Part A is suggested to originate from $X \equiv Y$ and $X=Y=Z$ stretches in organic structures, where $X, Y$ and $Z$ may represent any of the atoms $\mathrm{C}, \mathrm{N}, \mathrm{O}$ and $\mathrm{S}$ [66]. The differences in intensity between the two regions of the $\mathrm{SiO}_{2}$-coated IONP exposed sea urchin reflect differences in composition, as discussed above, in relation to the IR active mode of $\mathrm{Mg}$ containing calcite.

Falugi et al. [35] conducted a toxicity study of IONPs $\left(\mathrm{Fe}_{3} \mathrm{O}_{4}\right)$ in adult sea urchins (P. lividus) and found that none of the adult sea urchin survived after 2 days of exposure to concentration of $10 \mathrm{mg} / \mathrm{L}$. In this work the $\mathrm{SiO}_{2}$-coated IONP $\left(\gamma-\mathrm{Fe}_{2} \mathrm{O}_{3}\right)$ exposed A. lixula sea urchins were exposed to $150 \mathrm{mg} / \mathrm{L}$ without significant mortality or deformation, which is a surprising result given the high concentration. A possible explanation for this observation could be that $\mathrm{SiO}_{2}$ coating prevents the $\mathrm{Fe}^{3+}$ ion leaching from $\gamma-\mathrm{Fe}_{2} \mathrm{O}_{3}$ core of IONP nanoparticles. This suggests that further studies of the toxicity and elemental distributions of capped versus uncapped nanoparticles would be valuable, as appropriate coatings may be an attractive route to mitigate nanoparticle toxicity.

\section{Conclusions}

The mapping capability of X-ray fluorescence (XRF) spectroscopy is demonstrated to be a highly effective tool for determining elemental distributions within biological organisms and hence the presence of nanoparticulate species incorporated due to environmental exposure. Sea urchin larvae exposed to alkylated silicon nanocrystals (concentration of $\sim 7.2 \mathrm{mg} / \mathrm{L}$ ) measured $51 \mathrm{~h}$ after fertilisation show clear evidence of nanocrystal concentration within the organism and that those nanocrystals remain broadly intact. Moreover, a general increase in 'background' (i.e., non-skeletal) 
oxygen is observed which may be attributed to the end product of reactive oxygen species produced due to toxicity of the nanocrystals.

Exposure of sea urchins to high concentrations of silica-coated iron oxide nanoparticles $\left(\gamma-\mathrm{Fe}_{2} \mathrm{O}_{3}\right.$ nanoparticles coated with ultra-thin silica named here ' $\mathrm{SiO}_{2}$-coated IONPs' - at concentration of $\sim 150 \mathrm{mg} / \mathrm{L}$ ) is also observed to lead to agglomeration or material accumulation. However, the response of the sea urchins is found to be qualitatively different to that found for alkyl-SiNC exposure: there is no significant increase in background oxygen concentration in XRF maps but FTIR spectra do provide evidence of an increase in the presence of sulphur-containing compounds. Excess sulphur may be the result of a biological response to reduce the toxicity of these nanomaterials. However, despite this response, there is little mortality and deformation observed even though the concentration of $\mathrm{SiO}_{2}$-coated IONPs is so high. This result highlights the potential for coatings to reduce nanoparticle toxicity, opening up a wider range of materials for potentially safe use.

\section{Acknowledgments}

We thank the EU COST action TD0903 BioMineralix for funding and support, and ONE North East for nanotechnology funding at Newcastle. XRF and FTIR studies are supported by ELETTRA (Project EC-887). SP would like to thank the Royal Thai Government for a scholarship. We thank Prof. D. Makovec for the silica-coated iron oxide nanoparticles $\left(\mathrm{SiO}_{2}\right.$-coated IONPs).

\section{References}

[1] V. Torres-Costa, R.J. Martín-Palma, Application of nanostructured porous silicon in the field of optics. A review, J. Mater. Sci. 45 (2010) 2823-2838.

[2] Y. He, C. Fan, S-T. Lee, Silicon nanostructures for bioapplications, Nano Today 5 (2010) 282295.

[3] A.K. Gupta, M. Gupta, Synthesis and surface engineering of iron oxide nanoparticles for biomedical applications, Biomaterials 26 (2005) 3995-4021.

[4] N. O'Farrell, A. Houlton, B.R. Horrocks, Silicon nanoparticles: applications in cell biology and medicine. Inter. J. Nanomed. 1 (2006) 451-472.

[5] J.M. Perez, Iron oxide nanoparticles: Hidden talent. Nature Nanotechnology 2 (2007) 535-536.

[6] S. Laurent, D. Forge, M. Port, A. Roch, C. Robic, L.V. Elst, R.N. Muller, Magnetic iron oxide nanoparticles: Synthesis, stabilization, vectorization physicochemical characterizations and biological applications, Chem. Rev. 108 (2008) 2064-2110.

[7] A.S. Teja, P-Y. Koh, Synthesis, properties, and applications of magnetic iron oxide nanoparticles, Progr. Cryst. Growth Character. Mater. 55 (2009) 22-45.

[8] OECD. 2010. No.27-ENV/JM/MONO(2010)46, List of manufactured nanomaterials and list of endpoints for phase one of nanomaterials: Revision, Available at:

http://www.oecd.org/document/53/0,3746,en_2649_37015404_37760309_1_1_1_1,00.html

[9] N. Kobayashi, Marine pollution bioassay by using sea urchin eggs in the Tanabe Bay, Wakayama Prefecture, Japan, 1970-1987, Mar. Pollut. Bull. 23 (1991) 709-713.

[10] K.J. Kroeker, R.L. Kordas, R.N. Crim, R.N., G.G. Singh, Meta-analysis reveals negative yet variable effects of ocean acidification on marine organisms, Ecol. Lett. 13 (2010)1419-1434.

[11] B.R. Jasny B.A. Prunell The glorious sea urchin - Introduction, Science 314 (2006) 938.

[12] F.H. Wilt, Developmental biology meets materials science: Morphogenesis of biomineralized structures, Dev. Biol. 280 (2005) 15-25.

[13] R. Bonaventura, V. Poma, R. Russo, F. Zito, Effects of UV-B radiation on development and hsp70 expression in sea urchin cleavage embryos, Mar. Biol. 149 (2006) 79-86. 
[14] V. Matranga, F. Zito, C. Costa, R. Bonaventura, R., S. Giarrusso, S., F. Celi, Embryonic development and skeletogenic gene expression affected by X-rays in the Mediterranean sea urchin Paracentrotus Lividus, Ecotoxicology 19 (2010) 530-537.

[15] N.H. Alsharif, C.E.M. Berger, S.S. Varanasi, Y. Chao, B.R. Horrocks, H.K. Datta, Alkylcapped silicon nanocrystals lack cytotoxicity and have enhanced intracellular accumulation in malignant cells via cholesterol-dependent endocytosis, Small 5(2) (2009) 221-228.

[16] Shiohara, S. Handa, S. Prabakar, K. Fujioka, T.H. Lim, K. Yamamoto, P.T. Northcote, R.D. Tilley, Chemical Reactions on Surface Molecules Attached to Silicon Quantum Dots, J. Am. Chem. Soc. 132 (2010) 248-253.

[17] L. Ruizendaal, S. Bhattacharjee, K. Pournazari, M. Rosso-Vasic, L.H.J. de Haan, G.M. Alink, A.T.M. Marcelis, H. Zuilhof, Synthesis and cytotoxicity of silicon nanoparticles with covalently attached organic monolayers, Nanotoxicology 3 (2009) 339-347.

[18] H. Zuilhof, S. Bhattacharjee, A.T.M. Marcelis, I. Rietjens, G.M. Alink, S. Kauzlarich, M. Singh, T. Atkins, S. Regli, J. Veinot, R. Clark, A. Shukaliak, M. Fink, T. Purkait, B. Mitchell, Z. $\mathrm{Xu}$, Cytotoxicity of Surface-funcionalized Silicon and Germanium Nanoparticles: The Dominant role of Surface Charges, Nanoscale 5(11) (2013) 4870.

[19] A.D. Durnev, A.S. Solomina, N.O. Daugel-Dauge, A.K. Zhanataev, E.D. Shreder, E.P. Nemova, O.V. Shreder, V.A. Veligura, L.A. Osminkina, V.Y. Timoshenko, S.B. Seredenin, Evaluation of genotoxicity and reproductive toxicity of silicon nanocrystals, Bull. Exp. Biol. Med. 149(4) (2010) 445-449.

[20] J-H. Park, L. Gu, G. von Maltzahn, E. Ruoslahti, S.N. Bhatia, M.J. Sailor, Biodegradable luminescent porous silicon nanoparticles for in vivo application, Nat. Mater. 8 (2009) 331-336.

[21] L. Stanca, S.N. Petrache, M. Radu, A.I. Serban, M.C. Munteanu, D. Teodorescu, A.C. Staicu, C. Sima, M. Costache, C. Grigoriu, O. Zarnescu, A. Dinischioutu, Impact of silicon-based quantum dots on the antioxidative system in white muscle of Carassius auratus gibelio, Fish Physiol. Biochem. 38 (2012) 963-975.

[22] S.N. Petrache, L. Stanca, A.I. Serban, C. Sima, A.C. Staicu, M.C. Munteanu, M. Costache, R. Burlacu, O. Zarnescu, A. Dinischioutu, Structural and Oxidative Changes in the Kidney of Crucian Carp Induced by Silicon-Based Quantum Dots, Int. J. Mol. Sci. 13(8) (2012)10193-10211.

[23] L. Stanca, S.N. Petrache, A.I. Serban, A.C. Staicu, C. Sima, M.C. Munteanu, O. Zarnescu, D. Dinu, M. Costache, A. Dinischioutu, Interaction of silicon based quantum dots with gibel carp liver: oxidative and structural modifications, Nanoscale Res. Lett. 8 (2013) 254.

[24] M. Mahmoudi, H. Hofmann, B. Rothen-Rutishauser, A. Fetri-Fink, Assessing the in vitro and in vivo toxicity of superparamagnetic iron oxide nanoparticles, Chem. Rev. 112 (2012) 2323-2338.

[25] H.L. Karlsson, J. Gustafsson, P. Cronholm, L. Möller, Size-dependent toxicity of metal oxide particles-A comparison between nano- and micrometer size, Toxicol. Lett. 188 (2009) 112-118.

[26] S. Naqvi, M. Samim, M.Z. Abdin, F.J. Ahmed, A.N. Maitra, C.K. Prashant, A.K. Dinda, Concentration-dependent toxicity of iron oxide nanoparticles mediated by increased oxidative stress, Int. J. Nanomed. 5 (2010) 983-989.

[27] M. Mahmoudi, S. Laurent, M. Shokrgozar, M. Hosseinkhani, Toxicity evaluations of superparamagnetic iron oxide nanoparticles: Cell 'vision' versus physicochemical properties of nanoparticles, ACS NANO 5(9) (2011) 7263-7276.

[28] B. Szalay, E. Tátrai, G. Nyíró, T. Vezér, G. Dura, Potential toxic effects of iron oxide nanoparticles in in vivo and in vitro experiments, J. Appl. Toxicol. 32 (2012) 446-453. 
[29] L. Gu, R.H. Fang, M.J. Sailor, J-H. Park, In vivo clearance and toxicity of monodisperse iron oxide nanocrystals, ACS NANO 6(6) (2012) 4947-4954.

[30] X. Zhu, S. Tian, Z. Cai, Toxicity assessment of iron oxide nanoparticles in zebrafish (Danio rerio) early life stages, PLoS One 7 (2012) e46286.

[31] E. Kadar, D.M. Lowe, M. Sole, A.S. Fisher, A.N. Jha, J.W. Readman, T.H. Hutchinson, Uptake and biological responses to nano-Fe versus soluble $\mathrm{FeCl}_{3}$ in excised mussel gills, Anal. Bioanal. Chem. 396 (2010) 657-666.

[32] E. Kadar, F. Simmance, O. Martin, N. Voulvoulis, S. Widdicombe, S. Mitov, J.R. Lead, J.W. Readman, The influence of engineered $\mathrm{Fe}_{2} \mathrm{O}_{3}$ nanoaprticles and soluble $\mathrm{FeCl}_{3}$ iron on the developmental toxicity caused by $\mathrm{CO}_{2}$-induced seawater acidification, Environ. Pollut. 158 (2010) 3490-3497.

[33] N. Kobayashi, H. Okamura, Effects of heavy metals on sea urchin embryo development. Part 2. Interactive toxic effects of heavy metals in synthetic mine effluents, Chemosphere 61 (2005) 1198-1203.

[34] G. Pagano, E. His, R. Beiras, A.D. Biase, L.G. Korkina, M. Iaccarino, R. Oral, F. Quiniou, M. Warnau, N.M. Trieff, Cytogenetic, developmental, and biochemical effects of aluminium, iron, and their mixture in sea urchins and mussels, Arch. Environ. Contam. Toxicol. 31 (1996) 466-474.

[35] C. Falugi, M.G. Aluigi, M.C. Chiantore, D. Privitera, P. Ramoino, M.A. Gatti, A. Fabrizi, A. Pinsino, V. Matranga, Toxicity of metal oxide nanoparticles in immune cells of the sea urchin, Mar. Environ. Res. 76 (2012) 114-121.

[36] L.H. Lie, M. Duerdin, E.M. Tuite, A. Houlton, B.R. Horrocks, Preparation and characterization of luminescent alkylated-silicon quantum dot, J. Electroanal. Chem. 538-539 (2002)183-190.

[37] M.M. Rahman, S.B. Khan, A. Jamal, M. Faisal, A.M. Aisiri, '3 Iron oxide nanoparticles' in 'Nanomaterial', eds Rahman M. InTech: (2011) 43-66.

[38] W. Wu, Q. He, C. Jiang, Magnetic iron oxide nanoparticles: Synthesis and surface functionalization strategies, Nanoscale Res. Lett. 3 (2008) 397-415.

[39] S. Kralj, D. Makovec, S. Čampelj, M. Drofenik, Producing ultra-thin silica coatings on ironoxide nanoparticles to improve their surface reactivity, J. Magn. Magn. Mater. 332 (2010) 18471853.

[40] F.M. Dickinson, T.A. Alsop, N. Al-Sharif, C.E.M. Berger, H.K. Datta, L. Šiller, Y. Chao, E.M. Tuite, A. Houlton, B.R. Horrocks, Dispersions of alkyl-capped silicon nanocrystals in aqueous media: photoluminescence and ageing, Analyst 133 (2008) 1573-1580.

[41] Y. Chao, S. Krishnamurthy, M. Montalti, L.H. Lie, A. Houlton, B.R. Horrocks, L. Kjeldgaard, V.R. Dhanak, M.R.C. Hunt, L. Šiller, Reactions and luminescence in passivated Si Nanocrystallites induced by vacuum ultraviolet and soft-x-ray photons, J. Appl. Phys. 98 (044316) (2005) 1-8.

[42] Y. Chao, L. Šiller, S. Krishnamurthy, P.R. Coxon, U. Bangert, M. Gass, L. Kjeldgaard, S.N. Patole, L.H. Lie, N. O'Farrell, T.A. Alsop, A. Houlton, B.R. Horrocks, Evaporation and deposition of alkyl-capped silicon nanocrystals in ultrahigh vacuum, Nat. Nanotechnol. 2 (2007) 486-489.

[43] P. Coxon, Y. Chao, B.R. Horrocks, M. Gass, U. Bangert, L. Šiller, Electron energy loss spectroscopy on alkylated silicon nanocrystals, J. Appl. Phys. 104 (084318) (2008) 1-8.

[44] L. Šiller, S. Krishnamurthy, L. Kjeldgaard, B.R. Horrocks, Y. Chao, A. Houlton, A.K. Chakraborty, M.R.C. Hunt, Core and valence exciton formation in x-ray absorption, x-ray emission and x-ray excited optical luminescence from passivated Si nanocrystals at the $\mathrm{Si} \mathrm{L}_{2,3}$ edge, J. Phys.Condens. Mat. 21 (095005) (2009) 1-8. 
[45] S. Kralj, M. Drofenik, D. Makovec, Controlled surface funtionalization of silica-coated magnetic nanoparticles with terminal amino-and carboxyl groups, J. Nanopart. Res. 13 (2011) 2829-2841.

[46] B. Kaulich, J. Susini, C. David, E. Di Fabrizio, G. Morrison, P. Charalambous, et al., A European Twin X-ray Microscopy Station Commissioned at ELETTRA in Proceeding of 8th International Conference on X-ray micros Edited by Aoki S, Kagoshima Y, Suzuki Y, Conf Proc Series IPAP 7 (2006) 22-25.

[47] A. Gianoncelli, G.R. Morrison, B. Kaulich, D. Bacescu, J. Kovac, Scanning transmission X-ray microscopy with a configurable detector, Appl. Phys. Lett. 89 (2006) 25.

[48] A. Sole, E. Papillon, M. Cotte, Ph. Walter, J. Susini, A multiplatform code for the analysis of energy-dispersive X-ray fluorescence spectra, Spectrochim. Acta B 62 (2007) 63-68.

[49] E. Carlisle, Si: and essential element for the chick, Science 178 (1972) 619-621.

[50] F.H. Wilt, Matrix and mineral in the sea urchin larval skeleton, J. Struct. Biol. 126 (1999) 216-226.

[51] C. Jones, D.W. Grainger, In vitro assessments of nanomaterial toxicity, Adv. Drug Deliver. Rev. 61(6) (2009) 438-456.

[52] D.D. Stefano, R. Carnuccio, M.C. Maiuri, Nanomaterials toxicity and cell death modalities, J. Drug Deliver. (ID167896): 1-14.

[53] K. Fujioka, M. Hiruoka, K. Sato, N. Manabe, R. Miyasaka, S. Hanada, A. Hoshino, R.D. Tilley, Y. Manome, K. Hiraduri, K. Yamamoto, Luminescent passive-oxidized silicon quantum dots as biological staining labels and their cytotoxicity effects at high concentration, Nanotechnology 19(415102) (2008) 1-7.

[54] S.P. Low, K.A. Williams, L.T. Canham, N.H. Voelcker, Generation of reactive oxygen species from porous silicon microparticles in cell culture medium, J. Biomed. Mater. Res. Part A 93 A(3) (2010) 1124-1131.

[55] S. Piticharoenphun, L. Šiller, M-L. Lemloh, M. Salome, M. Cotte, B. Kaulich, A. Giononcelli, B.G. Mendis, U. Bangert, N.R.J. Poolton, B.R. Horrocks, F. Brümmer, D. Medaković, Agglomeration of silver nanoparticles in sea urchin, Int. J. Environ. Pollut. Remed. 1(1) (2012) 4450 .

[56] X. Long, M. Nasse, Y. Ma, L. Qi, From synthetic to biogenic Mg-containing calcites: a comparative study using FTIR microspectroscopy, Phys. Chem. Chem. Phys. 14 (2012) 2255-2263.

[57] J. Liu J, R.H. Hurt, Ion release kinetics and particle persistence in aqueous nano-silver colloids, Environ. Sci. Technol. 44 (2010) 2169-2175.

[58] S. Ayata, H. Yildiran, Optimization of extraction of silver from silver sulphide concentrates by thiosulphate leaching, Miner. Eng. 18 (2005) 898-900.

[59] D. Feng D, J.S.J. van Deventer, Effect of thiosulphate salts on ammoniacal thiosulphate leaching of gold, Hydrometallurgy 105 (2010) 120-126.

[60] A. Barth, The infrared absorption of amino acid side chains, Progr. Biophys. Mol. Biol. 74 (2000) 141-173.

[61] L.K. Tamm, S.A. Tatulian, Infrared spectroscopy of proteins and peptides in lipid bilayers, Quarter. Rev. Biophys. 30(4) (1997) 365-429.

[62] J.P. Davis, G.C. Stephens, Regulation of net amino acid exchange in sea urchin larvae, Am. Physiol. Soc. 247 (1984) R1029-R1037.

[63] R.M. Roat-Malone '1 Inorganic chemistry essentials' in 'Bioinorganic Chemistry-A Short Course', $2^{\text {nd }}$ edition. John Wiley \& Sons, Inc. (2007) 1-28. 
[64] T. Gustafson, M.B. Hjelte, The amino acid metabolism of the developing sea urchin egg, Exp. Cell Res. 2(3) (1951) 474-490.

[65] B.J. Fry, P.R. Gross, Patterns and rates of protein synthesis in sea urchin embryos: II. The calculation of absolute rates, Dev. Biol. 21 (1970) 125-146.

[66] G. Socrates, Infrared Characteristic Group Frequencies: Tables and Charts. $2^{\text {nd }}$ edition. John Wiley \& Sons Ltd. 1994. 